\title{
Research on the Innovation and Applications on Sports Equipment Ning $\mathrm{Li}^{1, \mathrm{a}}$ \\ ${ }^{1}$ Qinhuangdao Institute of Technology, Qinhuangdao, hebei, China \\ a845023430@qq.com
}

\section{Keywords: Sports Equipment, Innovation, Applications}

\begin{abstract}
Sports equipment is the indispensable material conditions engaged in sports activities. Practices with sports equipment can enhance students' muscle strength and improve the flexibility and coordination of the body. And it can also train students' brave and indomitable will and help them overcome mental difficulties. Currently, the status quo of the school sports equipment is they are according to the formal requirements of multi-sports projects no matter primary schools or middle school. But the problem is these formal athletic programs are setting professional athlete as the standard, and they are incompatible of the students both in psychological and physiological characteristic. While these commonly used instruments in general schools are also relatively old or scarce and the investment funds to purchase instrument of school are rarely and this leads to instrument cannot develop normally. So it is essential to do the research on innovation and application of sports equipment.
\end{abstract}

\section{Introduction}

With the improvement of the level of economic development and progress of social life, people's degree of concern for the health gradually improved, "Health First, lifetime sports" has developed into a new era of sports theme. With the ever-increasing sports items, sports equipment innovation has put forward new demands. Traditional sports equipment obviously does not meet the development requirements of the new era and innovation and reform have become the trend of the times of sports equipment application.

\section{The Meaning and Role of Sports Equipment}

Sports equipment is used in sports and fitness workout facilities, equipment, and supplies. With the continuous improvement of people's health awareness, making the sport gradually become popular, daily life, which is the development of sports equipment put forward higher requirements. The emergence of new sports to strengthen the linkages sports equipment and sports between. Stable performance, excellent quality and secure sports equipment not only to enhance the public's interest in sports, and to improve the level of people's movement to some extent. Physical exercise and fitness inseparable material conditions, and sports equipment is one of the important material conditions. The use of sports equipment to improve people's physical coordination and flexibility, increase muscle strength, meanwhile, can help foster a strong will. The use of sports equipment can make people get a wide range of exercise and training, can be said to be a key element of sports items indispensable [1].

\section{The Current Status of Sports Equipment Applications}

The Shortage of Sports Equipment. In many places, due to lack of funding for education, leading to a serious shortage of school sports equipment, the use of equipment is often purchased many years ago, a large proportion of the instruments are in a state of serious damage or imminent damage, plus management of confusion on the instrument, the user PE teachers in most schools is both devices is the manager, resulting in some equipment because it is not timely maintenance becomes waste, such as discarded hurdles frame, rusty shot and so on. There are some equipment to become private property, but only a handful of genuine use of the equipment. 
The Sports Equipment Utilization is Low. As Risk-free teaching. Concept promoted in high school physical education in most schools and students in physical education teachers worry too much because sports equipment operation errors caused by accident, so try to avoid physical education teaching technology difficult, dangerous, may cause harm to the teaching instrument even in the teaching process does not use basic equipment, resulting in high school physical education, there is a large part of the equipment to be shelved in the side, did not play its due role.

The Sports Equipment Teaching Method is Single. Most physical education teachers teaching thinking limited to a fixed mode of teaching, often only watch sports equipment inherent in the nature of property, while ignoring its potential properties, to a certain extent, resulting in a waste of resources. For example, in addition to hurdle hurdles can also be used to do. Small football door. Can also be used as a drill more obstacles, etc.; throwing medicine balls can be used in addition to, but also as a teaching and game markers, obstacles, etc.; rubber band in addition to playing games to jump, but also can be used for Rally training students in the arms, hierarchical jump exercises; sandbags can be done in addition to the game. Played. . Fight snails. , Kicking sandbags, you can also. Race with. Too far away to see who voted; so. Rational use of sports equipment, both on the re-use of limited resources, but also saves an effective way of sports resources [2].

\section{The Innovative and Specific Applications of Sports Equipment}

Development of sports equipment in the sport is not perfect, there are many aspects need improvement and innovation. Traditional sports equipment limited number of huge size, not easy to carry, is not conducive to the promotion of the use. To enhance people's sports concept, innovative sports equipment will be carried out. Innovative sports equipment can stimulate people's interest in sport and will help promote the popularity of sport

The Innovation and Application of Light Equipment. Light equipment is most likely to gain popularity and promotion of sports equipment, in sport on light equipment innovation, can enhance people's interest in sports. Light sports equipment range is very wide, you can take advantage of life items to innovation and transformation. For example, the use of waste cans or bottles made into a dumbbell, which is loaded in the right amount of gravel that can readily be placed to facilitate the movement of the location, at any time exercise; clothing can also make use of waste handmade football, inside with a soft material filled. Life objects can be utilized, made into a portable light sports equipment, which can not only increase people's interest in sports, but also to cultivate the awareness of innovation[3].

Traditional small rural kindergarten in sports equipment such as shuttlecock, ropes, ball, windmill, sandbags, gymnastic rings, light and exquisite, easy to use, the kids really like it, but over time, children would have no interest. So can every so often, in the above plus some new equipment, or add a new component flexibility on the same kind of equipment, inspire children to change the play. For example coupled with sandbags half Sprite, were throwing and catching activities; ball coupled with a small stick, turned into a "catch pig" and so on.

The Innovation and Application of Used Sports Equipment. Sports equipment that is commonly used in everyday sports people often come into contact with sports equipment or equipment. Development and use in the original motion capabilities to maximize the functionality of existing sports equipment. Reasonable innovations and improvements to the original function can be improved, to compensate for the defect, there is conducive to promoting the development of sports equipment. For example, the now popular. Long has style table tennis bat. Is the original horizontal position and Penhold improved and integrated, draw a new racket this new racket in front of the original racket handle an additional grip with the thumb and forefinger coincide small handle, this pair improved grip makes the racket can be more widely used, easy to carry out in-depth sports items. For commonly used sports equipment innovations to improve the promotion of the sport, increase people's enthusiasm.

The Innovation and Application of Living Appliances. Sport is a mass of sport, but not limited ages, different sports have different preferences populations in different populations use different sports equipment, through the everyday life of mining equipment and improved 
functionality, to innovate a variety of practical and convenient sports equipment. For example, commonly used in people's daily lives bike, its innovation and transformation, you can become a sports equipment. According to the basic principles of bicycle innovation on the structure and function, it is possible to develop a new product. Innovative use of different bike models the size of the wheel wheelbarrow, wheelbarrow high flexibility, can enhance flexibility and coordination body of the people to some extent, improve people's physical fitness, and thus serve the purpose of physical exercise.

Using life in a variety of waste materials is an effective way to enrich the kind of small sports equipment. On the one hand, inspire children clever use of all kinds of waste materials, such as encouraging children from their homes with some scrap cardboard, cut a round, square and so on. Then in the above draw their favorite designs, colorful "flying saucer" was born; also allows children to use scrap cardboard, according to his own hand type cut only a "small hands", fitted with elastic bands, children wear it they can freely learn critters crawling flutter [4].

Homemade instruments for its economic, convenient, strong, handsome features, more and more teachers attention. By using homemade instruments to carry out research activities, physical exercise, kindergarten outdoor two hours to carry out activities to flourish. At the event, teachers correctly handle the relationship between teacher and child-led body, get rid of the past, "I'll teach you to learn" concept, more leading role of teachers in the creation of environment for providing materials and other aspects of early childhood development guide reflected. At the event, new equipment to improve the children participate in activities of interest, their initiative and creativity to get a lot of play. In "Let each child succeed," the concept to guide young children to explore the chances of success increase, they dare to try new methods, self-confidence and willpower has been enhanced greatly improved activity atmosphere, truly received the effectiveness of activities.

The Innovation and Application of the Equipment in Sports Teaching. For high school physical education in sports equipment innovation, but also an important part of sports equipment innovation, innovate teaching instruments can enhance students' interest in learning, enhance teaching effectiveness. In traditional teaching, basketball is a sport loved by students, basketball equipment for innovation, you can use the lift basketball, mobile basketball, basketball rings without board or a board more than three times basketball, etc., this new reform can stimulate the curiosity of students and attract students to participate in sports; volleyball popularization and promotion, the use of U-volleyball nets, volleyball can lift racks; or have additional features and local folk traditions of sports equipment, are able to stimulate students' interest in sports to achieve in sports promotion. Through sports equipment innovation and reform, both to achieve the promotion of original sports equipment function, but also can stimulate people's enthusiasm for sports projects. Simple and practical sports equipment to facilitate future popularization and promotion, can make people more deeply implement the concept of lifelong physical, achieve universal participation in sports in the past.

The Innovation and Application of the Site Instruments. We should fully play the role of the existing instruments and give full play to the role of existing instruments. For example: when doing sports acrobatics, from heel cushions can be changed horizontally, before this practice roll, backward roll, kneel jump, shoulder and elbow inverted, head handstand etc, can a student from the original piece of mat exercises, while the increase for the two students to practice (this, density and volume movement classes doubled). Another example is the horizontal bar hopped on a positive support, the support placed under a single hanging knee, single (double) pedal to turn on to support such action, can be two people on a horizontal bar to practice [5].

Think of ways to alternative instruments. To compensate the lack of instruments, we should promote the use of alternative instruments. For example on the side box horse vault, straddle vault etc, can be done on the goat, goat's length and width is not enough, you can bring with Larsson tight lengthened symbolically, widened. Before some action on the horizontal bar, such as the low bar overhang, jumped support after swing, the swing ride back brace front legs to stand under the swivel 90 degrees and other actions can be carried out exercises on parallel bars on the side bar, parallel bars support under the backswing swing and can also be used under suppression box swing 
back leg brace on vault and vault stoop swing leg brace instead. Alternative exercise equipment movements, sometimes though not completely replace the original materials, but the task is completed courses have some role in promoting.

\section{Conclusions}

In summary, the integration of people's creative thinking in innovative sports equipment makes seemingly ordinary materials can make the best use in physical education and then we can achieve comprehensive development and utilization of existing resources. In this way we can both solve the status quo of shortage of school sports equipment, but also mobilize the enthusiasm of the students' physical education. And we can make it better for sports teaching service, thus promoting the formation of the concept of lifelong physical and better enhance the quality of people's mental and physical.

\section{References}

[1] Kunxia Wang: Early Education, Vol. 7 (2010) No 17, p.57-59

[2] Xiaohong Mu: Early Education, Vol. 12 (2004) No 12, p.22-24

[3] Yuzhong Wang: Tangdu Journal, Vol. 1 (2001) No 33, p.11-14

[4] Yang Guo: Primary School Age, Vol. 10 (2010) No12, p.108-110

[5] Lingzhi Bu: Physical Education, Vol. 8 (2009) No 22, p.63-64 